\title{
Introduction: How Participation Relates to Science and Technology and How Science and Technology Shapes Participation
}

\author{
Harro Maat and Linda Waldman
}

Science and technology need society. Research and technology have little chance of influencing development if they do not anticipate societal effects and responses. Universities, research centres and technology institutes invest in a good relationship with the public. Engaging citizens creates a wider acceptance of (potentially) controversial scientific and technological developments. Policymakers therefore create platforms and processes for public engagement, as is the case, for example, with nanotechnology. Acceptance may refer to norms or ethical principles but may also be effective from a purely commercial concern. The consultation of potential customers at the early phase of product design often is a major step to success. An example is the Boeing 777 aircraft, developed in close consultation with eight major airlines. Client-oriented technology development and participatory research are global phenomena. The participatory agenda for science and technology is pushed by supra-national networks of companies, governmental bodies and nongovernmental organisations. It is also global in the sense that programmes to support participatory research and technology development can be found in countries across all continents.

Beneath the broad and general picture just sketched lies a range of issues and questions. How does participation relate to science and technology? What are the power relations between scientists, policymakers and members of the public? What types of scientific and technological decisions can be influenced through participation? And pushing it to the extreme, does society need science and technology? Clearly, science and technology is everywhere and we all take it for granted in our daily lives. Drinking water from a tap, or fetching water from a well; buying food from a supermarket or planting crops for subsistence, these activities all rely on scientific knowledge and technology. Science and technology are thus implicit in development assumptions about modernisation and economic growth. Nonetheless, we live in a rapidly changing world in which questions of risk, safety and innovation are paramount. Scientific expertise no longer can rely on its assumed inherent authority. News headlines frequently broadcast controversies about how people relate to and mobilise around topics such as climate change, genetically modified (GM) crops, cloning, new reproductive technologies and so forth. Innovative new measures - such as consensus conferences, citizens' juries and community-based environmental audits - have been adopted to encourage public participation and now frequently characterise science and policy processes not only within the industrialised north, but also within development contexts.

This IDS Bulletin brings together insights from Science and Technology Studies and Development Studies, two fields in which many of these questions and issues are taken up and investigated. Cases, concepts and analyses emerging from studies in developing and developed countries show much similarity and prove to be fruitful terrain for collaboration as the volume Science and Citizens edited by Leach et al. (2005) has shown. The initiative for this IDS Bulletin builds on the themes and issues picked up in the Leach et al. volume and poses the question: Do participatory processes operate differently when science and technological processes are involved and how might these processes be theorised? The initiative for this special IDS Bulletin 
also originated from a session at the conference meeting of the European Association for the Study of Science and Technology, held in Lausanne in August 2006. Earlier versions of several of the articles in this volume were first presented there. It was clear from that moment that the articles raise some important conceptual and empirical challenges, resulting from recent work.

Combining the fields of Science and Technology Studies and Development Studies implies the integration of an analysis of science and technology with an analysis of poverty, social injustice and global relations. Both fields can be considered as interdisciplinary, meaning that concepts and analytical approaches are drawn from various academic disciplines, primarily, though not exclusively, social science disciplines. The focus of this IDS Bulletin is on the question of how participation relates to science and technology. The analytical focus is one way to read the title of this IDS Bulletin (see below). All the articles explore processes of participation through examining practices in which science and technology play a prominent role. The articles examine the conditions under which wider society is able to contribute to debates about science and technology, about the governance of science and technology and about the corresponding developmental impacts of such engagements.

A clear contribution from the Development Studies field is that implications for the developing world are taken up explicitly. The articles address the difficulties participatory processes encounter when assessing scientific and technological problem-solving in the context of ongoing globalisation. By this, we do not imply that a global perspective or North-South relations are entirely absent in Science and Technology Studies. Where configurations of science, technology and society differ from one situation to the other, there is a difference in coverage of geographical, cultural and political settings between Development Studies and Science and Technology Studies. This plays out in the concepts and theoretical approaches developed in both fields. Rather than stressing divergence, the aim of this IDS Bulletin is to see how such variation can lead to fruitful combinations and a new conceptualisation based on a comparative, international perspective.

When the concept of 'participation' is scrutinised, it is clear that distinct traditions exist in both fields. The distinction is not in any way fundamental or rigid but is an effect of the different overall focus in the two fields. Within Science and Technology Studies the entry point of most analyses is the activity of scientists and engineers. Engagement of the public is usually examined in terms of how experts relate their work (and themselves) to a wider public and how the organisations they work for (universities, governments, companies etc.) help them to do so. In that respect the contribution from Maja Horst, Alan Irwin, Peter Healey and Rob Hagendijk (hereafter Horst et al.) in this IDS Bulletin has clear roots in Science and Technology Studies. At the same time, the work they present is certainly not a typical Science and Technology Study. Their focus on the relationship between the different forms of governance and participation expands the Science and Technology Studies agenda and opens up new horizons that explicitly address questions of policy and governance. Overall the typical Science and Technology Studies focus has been considerably broadened in recent years and it is no longer primarily the work of researchers or technical experts that matters (Oudshoorn and Pinch 2003).

From a Development Studies perspective, processes of participation are generally given a different twist. Emphasis is given to the inclusion of marginalised groups. A typical Development Studies definition of participation is 'ways in which poor people exercise voice through new forms of deliberation, consultation and/or mobilisation, designed to inform and to influence larger institutions and policies' (Gaventa 2002: 1). Despite the somewhat formal language, the definition clearly refers to a process of democratisation. The quoted definition being just one example, the participation agenda in Development Studies generally includes a programmatic or normative element. 'Policies informed by voices of the poor' should not only be understood as a statement of fact but also as a form of advice to policymakers. The programmatic element in the participation agenda of Development Studies gives many studies in the field a specific orientation and framing. As several authors in this IDS Bulletin point out, democratic values, although important, do not automatically provide appropriate analytical tools. Combining concepts and insights from Development Studies and Science and Technology Studies enables the authors of this IDS Bulletin to make several points regarding the participation agenda. 
Participation has a complicated relationship with democratisation or governance, the latter term indicating a broader category of relationships between those who govern and their constituencies. This comes out most directly in the article by Horst et al. The authors examine questions of European governance and participation, covering programmes for public engagement in science and technology in various countries across Europe. They point out that there is a widespread assumption that public participation is both valuable and necessary. The way the participatory programmes are implemented in the countries studied, however, show great variation. Moreover, implementation does 'not necessarily make policy formulation any easier - in fact quite the opposite. Deliberative engagement is therefore not a shortcut to the creation of social consensus'. An important cause linked to this outcome is that policymakers tend to overlook the extensive institutional requirements for participatory programmes to run in any appropriate form. As Horst et al. put it, 'rhetorical statements about the need for deliberation which do not also consider the full institutional implications of this mode are likely to lead to alienation and increased scepticism'.

From a different entry point but with a similar conclusion, the study presented by Dominic Glover shows that the participation agenda is relevant not only to governmental and pro-bono nongovernmental agencies. He analyses how in the Monsanto Company's Smallholder Programme issues of farmer participation, responsiveness and accountability were played out. He starts by reviewing how the 'farmer first' approach called for a new participatory method to agricultural research and extension as long ago as the 1980s, and has been refined and elaborated in subsequent decades. The lessons emerging from dialogue and experience with participatory 'farmer first' models did not, however, get translated into Monsanto's smallholder projects, which were designed and implemented in a top-down, expert-driven manner and aimed to 'educate' farmers about favoured GM crops.

Ultimately, the farmers' participation was limited to that of consumers of the company's know-how and technological products. Globally, however, Monsanto used the programme to publicise its vision of 'transforming agriculture in developing countries' and tried to establish Indian farmers and consumers as the rightful authorities to judge the benefits of GM crops. 'Seen in this light, the New Monsanto Pledge and the Smallholder Programme appear as key elements of a strategy to influence global public and policy debates about biotechnology in agriculture and development.'

The strong effects and complicating factors of the institutional context in which programmes for public engagement in science and technology operate is an element that is apparent in all contributions to this IDS Bulletin. Related to this, the articles also make clear that participatory processes operate differently when science and technology are involved. The second interpretation of this IDS Bulletin's title is that science and technology become key factors in participatory programmes and under certain conditions even operate as mechanisms for participation.

The latter interpretation is argued for most strongly in the article by Paul Richards on food security and postwar reconstruction in Sierra Leone. Richards distinguishes between deliberative forms of participation, involving rational persuasion (such as citizen juries or stakeholder consultations) and performative participation, which combines ritual, symbolism and what Richards describes as a 'musical' kind of process (examples range from political rituals to technological innovations). While conventional development has focused on deliberative participation, Richards argues for a combining of these two forms in order to mitigate against the elite capture of deliberative participation. He sustains his argument by examining a postwar food security project in Sierra Leone. As the staple crop, rice is produced and improved through complicated networks of seed exchange. Richards shows how communities displaced by the war were unable to maintain seed reciprocity - a process which sustained egalitarian cultural values - and agricultural innovation. Postwar humanitarian interventions boosted elite political values with its focus on patrimonial leadership. Richards argues that the linking of performative participation and deliberation is necessary to stimulate agrarian rehabilitation and to address the hierarchical nature of humanitarian intervention. Linking egalitarian processes of seed distribution with the performative rituals of peace and rights days, enhances participation and compensates for the exclusion of voices in the deliberative arena.

Linda Waldman's work in rural South African communities also draws a distinction between 
'formal' participation' in a multi-stakeholder Asbestos Forum and local, cultural ways of understanding and 'handling' asbestos pollution. She combines anthropological studies of risk with Richard's focus on the 'doing' of technology. Her study shows how former asbestos mineworkers' perspectives of risk influence the ways in which they approach their current work - cleaning up asbestos waste - and the safety measures taken on the job. The article not only confirms that local understandings and scientific approaches are interwoven but also makes clear that they become more interwoven when the activity of cleaning up asbestos waste is organised and performed in a relatively effective manner. Conversely, in situations where afflicted households, companies and local governments cannot effectively implement a cleaning strategy, views and understandings are more contradictory and divergent, drawing more on local, culturally informed understandings of risk and exposure.

Emphasising the 'participatory potential' of science and technology as emerging from these articles is an important move forward in the debate on the governance of science and technology. The question is usually framed as how science and technology can be governed more equitably, therewith implicitly saying that science and technology by default need a democratically controlled, restrictive environment in order to have any benefits for society in general and the global poor in particular. What various articles in this IDS Bulletin implicitly or explicitly point out is that the complex arrangements between science, technology and society require a different understanding of how participatory processes and issues of governance become or may become part of these arrangements. One concept, applied in two articles in this IDS Bulletin, that tries to deal with the complexity of technology, participation and governance is 'innovation systems'.

Harro Maat explores an issue-based understanding of participation, which is centred on emerging political processes. He argues that including an issue-centred notion of participation into an innovation systems approach results in a more effective understanding of participatory processes in relation to science and technology. Maat's article focuses on agricultural extension practices during the colonial era and, in particular, in the Netherlands Indies (now Indonesia). He argues that technical discussions about the organisation of research and about possible technical alternatives were not simply concerned with scientific processes but included a policy response to social unrest among the rural population. Within the colonial innovation system, actors voiced their concerns in technical rather than political terms Nevertheless, issue-driven politics and forms of participation were clearly influencing these technical concerns. Maat's historical examination of agricultural extension practices alerts academics and policymakers in Science and Technology Studies and Development Studies of the need for greater contextualisation of issue-driven participation in relation to technological processes, as this facilitates a better understanding of responsiveness and operational flexibility.

Joanna Chataway and James Smith also apply an innovation systems approach to understand participation. They focus on the International AIDS Vaccine Initiative $(I A V I)$, a pro-bono consortium of various actors aimed at a wide availability of AIDS medication in developing countries. They see participation as both a mechanism to build democracy and a way of achieving social and economic development. Building on Albert Hirschman's notions 'exit, loyalty and voice', they seek to demonstrate some of the complex relationships between the instrumentalist approaches of innovation systems and the creation of broader capacities. Chataway and Smith see the work of the IAVI not purely in instrumental terms, arguing that the consortium's focus on communication coupled with consumers' 'exit' possibilities leads IAVI to pay more attention to participation and to the needs of local communities. They show how the consortium actively pursues an inclusive strategy, taking up the issues of participation, but also argue that there remains a gap between company rhetoric and actual practice. The rhetorical devices and communications strategies that companies employ to 'deliberate about deliberation' may not actually facilitate participatory forums which engender change.

What comes out strongly in the article by Chataway and Smith as well as in other contributions to this IDS Bulletin is that participatory processes and social change and the interaction with scientific research and technology development are often long-term processes. This poses serious methodological difficulties to studies of such processes as presented in this IDS Bulletin. In general, the conditions in universities and research institutes are not very 
conducive to longitudinal studies. Time also appears a potential hurdle in the participatory process itself. As Chataway and Smith remark, an initiative like IAVI "operates under the threat of "exit" by donors, partners and a wide range of collaborators and supporters in different contexts'. When the structures set in place for participation do not or cannot deliver, the direct response is frustration and withdrawal. When innovation fails to occur, there is no alternative other than to rely on existing local explanations and practices.

\section{References}

Gaventa, J. (2002) 'Exploring Citizenship,

Participation and Accountability', IDS Bulletin 33.2: 1-11

Leach, M.; Scoones, I. and Wynne, B. (eds) (2005)

Science and Citizens: Globalization and the Challenge of Engagement, London: Zed Books
The overall argument emerging from the articles in this IDS Bulletin, is that bringing together Science and Technology Studies and Development Studies contributes to the participation debate not only by analysing it through scientific and technological practices. The articles also point out that scientific research and technology development have a participatory potential. Participation sometimes is, and more often can be, enhanced when science and technology are fully integrated with society and governance.

Oudshoorn, N. and Pinch, T. (eds) (2003) How Users Matter: The Co-Construction of Users and Technology, Cambridge: The MIT Press 